\title{
POLICY DIFFUSION IN COMMUNITY-SCALE FLOOD RISK MANAGEMENT
}

\author{
DOUGLAS S. NOONAN ${ }^{1}$, LILLIARD E. RICHARDSON ${ }^{2}$ \& ABDUL-AKEEM SADIQ ${ }^{3}$ \\ ${ }^{1}$ Indiana University-Purdue University, USA \\ ${ }^{2}$ Pennsylvania State University, USA \\ ${ }^{3}$ University of Central Florida, USA
}

\begin{abstract}
This study analyzes which communities adopted flood risk management practices during the past 25 years. In particular, we focus on community-scale flood management efforts undertaken voluntarily in towns and counties across the United States. In 1990, the US Federal Emergency Management Agency created the Community Rating System (CRS) to provide incentives to local governments to improve flood resilience. About 1,300 counties and cities voluntarily participate in the CRS, but most eligible communities do not participate. Here, we explore the factors shaping community CRS participation, such as flood risk, socio-economic characteristics, and economic resources, and we assess the competing phenomena of policy diffusion versus free riding. Previous models of community-scale flood mitigation activities have all considered each community's decision as independent of one another. Yet one community's flood management activities might directly or indirectly influence its neighbors' mitigation efforts. Spillover effects or "contagion" may arise if neighboring communities learn from or seek to emulate or outcompete early adopting neighbors. Conversely, stricter regulation in one community may allow its neighbors to capitalize on looser regulation either by attracting more development or enjoying reduced "downstream" flood risks. This paper presents a conceptual model that allows for multiple forces affecting diffusion, such as copycatting and learning from neighboring communities, free-riding on neighbors' efforts, and competing with neighbors to provide valuable amenities. We empirically test for these alternative diffusion pathways after controlling for the spatially correlated extant flood risks, building patterns, and demographics. The analysis integrates several large datasets to predict community flood risk management for all cities and counties in the US since 1990. Controls for local flood risk combined with a spatial lag regression model allow separate identification of alternative diffusion pathways. The results indicate strong evidence of copycatting and also suggest possible free-riding.

Keywords: flood management, flood risk, policy diffusion, community, local, spatial lag, spatial error.
\end{abstract}

\section{INTRODUCTION}

Flooding has long been a threat to communities, but risk management is a challenge for cities, states, and national government. In 1990, the US Federal Emergency Management Agency (FEMA) created the Community Rating System (CRS) to provide incentives to local governments to improve flood resilience. The CRS measures community flood management efforts, and flood insurance premiums are discounted accordingly. A number of factors shape community participation, including flood risk, fiscal capacity, and socioeconomic characteristics. Almost 1,300 communities voluntarily participated in the CRS in 2013, but there are over 22,000 communities in the National Flood Insurance Program (NFIP) who are eligible to join the CRS after undertaking additional management activities.

In this paper, we explore the factors shaping community CRS participation, and in particular we assess the competing phenomenon of policy diffusion versus free riding. Policy diffusion via spillover effects or a contagion model would suggest that neighboring communities would be more likely to adopt resilience efforts once one local community led the way, all else equal. City officials or concerned citizens could see the resilience efforts in a nearby community, want similar protection, and perhaps more easily follow in their 
footsteps by borrowing from their policy framework. Therefore, we would see contagion effects following early adopters.

Conversely, if tougher codes raise costs or at least are perceived to raise costs for businesses and residents, flood management efforts could put a community at a competitive disadvantage in terms of economic development or population expansion. Consequently, nearby communities could benefit from this competitive advantage versus a nearby early adopter. Further, the neighbor's risk mitigation efforts could reduce potential damage from floods for the nearby communities who do not participate so free-riding incentives would suggest that they not act.

Using FEMA data on CRS participation, US Department of Transportation data on flood risk at a $1 \mathrm{~km}$ cell level, and Census data for socioeconomic factors, we develop a model of policy adoption for CRS participation. We then enhance this model by adding in a spatial error and lag term to capture whether neighbors' adoption helps explain adoption in a community. It is possible that some negative correlation happens especially if "downstream" communities want to free ride on their upstream neighbors' proactive mitigation.

Overall, the results can contribute to the policy diffusion literature at the local community level, test for free-rider activity, and inform policymakers about the factors shaping the success of the CRS program.

\section{LITERATURE REVIEW}

Historically, top-down, command and control regulatory approaches have been criticized for their rigidity and costliness [1]-[3]. For example, [3] argues that some environmental regulations, such as the Clean Air Act, have increased organizations' operating costs, which in turn, undermined their productivity and reduced their profits. Owing to the ineffectiveness and costliness of command and control approaches, there has been a growing interest in using voluntary programs as a salient policy tool [4].

Despite the inherent benefits of voluntary programs by way of increased compliance rates, many federal voluntary programs find it hard to increase their compliance rates. Only a fraction of the potential 22,000 communities nationwide (less than 6\%) have achieved the minimum score (500 points) necessary to qualify for CRS level 9 . To make matters worse, there is no comprehensive framework to explain the reasons for such low compliance or participation rates. Before discussing the empirical setting for developing this framework, we briefly highlight the importance of the Community Rating System program in reducing the impacts of floods and strengthening communities' resilience to floods.

Globally, floods are considered one of the most destructive natural hazards in terms of lives lost, injuries, and economic losses [5]-[7]. In the United States, floods have posed, and continue to pose, considerable problems to communities [8], [9]. According to [10], on average over the previous 30 years there were 95 flood-related deaths and $\$ 8.2$ billion in flood damages in the United States between 1982 and 2011.

Although there is a flood risk management literature that looks at various topics related to the CRS - the determinants of community participation [7], [11], adaptive capacity [12], policy learning [13], non-linear incentive structure [9], and CRS effects on flood insurance demand [14], to our knowledge, there is no explicit and comprehensive theoretical framework that explains why local communities enroll in the CRS. Here, we draw on and integrate key insights from several research literatures to explore empirical determinants of adoption.

First, we borrow insights from the political-economy literature and examine the influence of political-economic factors on participation in the CRS. Second, the public finance literature is useful in helping us articulate the role of financial resources in community decisions regarding CRS participation. Third, the emergency/disaster management literature 
provides substantial empirical evidence that flood risk is an important predictor of community participation in the CRS [7], [11], [12], [15]. Fourth, the flood-risk-management literature demonstrates that communities participating in the CRS experience far less property damage from flood disasters than communities not participating in the CRS program. Fifth, there is a rich and extensive body of literature on voluntary environmental programs that provides justification for why private entities participate in federal voluntary environmental programs [16]-[22]. We extend that literature into the case of local governments opting into a voluntary, federal program - the Community Rating System.

The National Flood Insurance Program (NFIP) provides federally backed flood insurance for properties in floodplains where the local community enforce certain measures that regulate floodplain development and flood mitigation. The NFIP, however, is fraught with problems such as low insurance premium rates and increased development in floodplains [23]. As a result, flood losses are substantial and on the rise [23], [24]. To encourage communities to exceed the minimal rules set by the NFIP, FEMA developed a voluntary program that provides a point system for a set of community actions and policies that reduce flooding hazards and mitigate damages from flooding. Under the CRS, property owners in covered floodplains within communities may receive discounted flood insurance premiums with larger premium discounts available for those communities who rate better on the CRS.

FEMA established a set of CRS levels that range from ten to one (the best rating) with higher point totals moving a community up the scale, and the discounts start at level nine with a five percentage point reduction for each level on the CRS scale up to a $45 \%$ discount at level one for properties in the special flood hazard area. The communities in the NFIP can apply each year to FEMA for evaluation of the activities qualifying for various components of the CRS point system to qualify for higher levels, and property owners in the qualified coverage areas receive these discounts on their flood insurance. The communities seeking to earn CRS points have many options, which are placed into the four broad categories: public information activities, mapping and regulations, flood damage reduction activities, and warning and response. The various activities differ in their maximum points allowed as well as their main functions (e.g. informational, regulatory, altering infrastructure). Importantly here, they also differ in terms of whether a community's adoption might affect neighboring communities' flood risk and also in terms of how easily a neighbor might copy them.

\section{RESEARCH DESIGN}

To answer our research questions, our base model explores the factors that motivate communities to implement flood hazard mitigation activities. In general, our approach focuses on policy diffusion from one community to another. Mitigation activity represents any activity a community implements to reduce flooding hazard and mitigate the damage from flooding. The implementation of mitigation activity is a function of community flood risk, other community characteristics, and its neighbors' mitigation activities and other characteristics.

Community flood risk includes the community's natural environmental situation (e.g. topography, on a coast, in a swamp, in a valley, or on a river), population density in a flood plain, past flood experiences, weather patterns, and existing building patterns in flood plains. Community characteristics include items such as housing stock, housing value, real personal income, resident education levels, and poverty rates. The neighbor mitigation activities and characteristics are the same set of variables but moderated through the lens of diffusion and free-rider incentives.

For this study, community mitigation activities are measured using a community's adoption of CRS components. Our CRS data from FEMA begins in 1998, and we have point 
totals for adopting communities and CRS level for each year until 2013. Even though this is a small fraction of the potentially eligible cities and counties in the US, it does capture a large share of the population in flood plains. Over a thousand communities participated in the CRS, with several thousand more directly adjacent, making the policy diffusion question particularly salient for much of the data. Our base model operationalizes mitigation activities as a community's total CRS points in 2013, a continuous indicator of additional flood management activity and policy. Additional models are estimated, including one that predicts only changes in CRS score from 1998-2013, effectively switching from a cross-sectional model to a more dynamic one. Additional models that examine particular types of CRS activities (e.g., those easier to diffuse, those that affect neighbors' flood risks) can also be estimated, although space constraints limit discussion here.

The community flood risk and other characteristics are represented with an array of variables as described further below. Neighbor effects are addressed using a spatial mixed model (SMM), one that captures both a spatial lag and spatially autocorrelated errors, described below. The base regression model to be estimated is:

$$
\mathrm{y}=\rho \mathrm{Wy}+\beta \mathrm{X}+\delta \mathrm{E}+\gamma \mathrm{R}+\theta .
$$

In eqn (1), y represents the CRS point total in 2013 (or the change from 1998 to 2013 in a second model we estimate), where nonparticipating communities receive a 0 score. (Notably, some of those communities may still undertake relevant programs, just not such that they are in the CRS.) X is a vector of demographics from the Census (aggregated up to county/place level from tracts), typically measured in 2000 as the year closest to the 1998 start date for the CRS data. In eqn (1), E is a vector of environmental and geographic factors (e.g. topography, water cover, humidity, ruralness), while $\mathrm{R}$ represents flood risk measured using county-level flood damages from SHELDUS and from the USDOT (1996) flood risk map.

The model in eqn (1) allows for a spatial mixed model estimation, where $\rho \mathrm{Wy}$ is a spatial lag term, based on a (row standardized) spatial weights matrix $\mathrm{W}$ (in our case, an NxN matrix indicating whether any pair of observations are "neighbors" with a 1 and a 0 otherwise). We define $\mathrm{W}$ based on simple contiguity so that the Wy term basically amounts to an average value of $y$ among all of community i's adjacent communities. The parameter $\rho$ is thus a spatial lag parameter that reflects the direct spillover influence of neighbors' $y$ values on one's own y value. We expect a significant and positive $\rho$, and the regression allows us to test that hypothesis. Wy is endogenous, so the estimator relies on a set of valid instruments based on the spatial lags of all the other regressors. The error term $\theta$ in eqn (1) can also be estimated with a spatial error component: $\theta=\lambda \mathrm{W} \varepsilon+\varepsilon$, where the $\lambda$ is the spatial autocorrelation parameter and the "nuisance" or error term is allowed to correlate among neighbors. Essentially, this tests for some omitted variables that tend to cluster or correlate spatially. Restricting $\rho$ and $\lambda$ to both be zero allows for eqn (1) to be estimated using conventional ordinary least squares (OLS).

\section{DATA}

Seven different secondary data sources are combined to test the hypotheses. These data sources are CRS participation data (1998-2013) from FEMA, Geolytics (geolytics.com) Neighborhood Change Database (tract-level Census data, 1970-2010), the Spatial Hazard Events and Loss Database for the United States (SHELDUS) (1960-2014), FEMA's latest Digital Flood Insurance Rate Maps, demographic data from the Census Bureau (1992-2012), county-level climate and topology measures from the US Department of Agriculture's Natural Amenities Index, and high-resolution raster-map (1 km grid cell) flood risk data from 
US Department of Transportation [25]. Each are mapped using GIS for the whole US and resolved to the city and county level units (i.e. some units overlap) using current boundaries.

The dependent variables shape the type of method possible as well as the subsample of the overall data set that can be assessed in each case. The summary statistics for the dependent variables are in the first few rows of Table 2. Our CRS data from FEMA begins in 1998, and we have point totals for adopting communities and the CRS level for each year until 2013. While Total13 indicates a mean score of only 77, this is weighted downward by a great majority of communities that do not participate and thus receive a score of 0 . Similarly, $\Delta$ Total has a relatively small value (46.2), owing to most communities not participating in both 1998 and 2013. Notably, the mean CRS score among the participating communities in 2013 is 1,552 . This is up from a mean of 950 among the participating communities in 1998, even as the number of participating grew by over $40 \%$. Because many of the early adopters in the 1998 cohort remained in the program, nearly five percent of the communities were in CRS in 2013.

The description of the independent variables is also in Table 1, and the summary statistics are in Table 2. In general, the first few variables are demographic variables (e.g. population density, percent college educated, poverty rate, housing values), followed by environmental variables (humidity, water share, and topography) and flood risk variables (Raster Map $1 \mathrm{~km}$ grid cell, flood plain share, flood damage). The demographic controls include initial level measures (circa 2000) as well as percent changes from 2000 to 2010 to capture recent trends and not just level effects. Using flood risk data from the raster maps in the 1990s has the advantage of mitigating potential endogeneity in official flood insurance rate maps, but still requires aggregating up from the $1 \mathrm{~km}$ grid cell to the community level. Community flood risk here is thus measured using the weighted average of tract-level flood risks, with weights defined by tracts' area and also by tract population. Trends in flood risk - both in terms of recent flood event damage and in terms of changing population flood risk - are also included in the model. It is important to note that FloodDam59890 captures changes in the past five years of flood damages, while RiskshareP9890 essentially captures shifts in population toward flood-prone areas, as the flood risk measure itself is time invariant.

\section{RESULTS}

The results in Table 3 show how collectively important the various control variables are. Communities that participate in the CRS tend to have had lower population densities, higher education levels, and more population turnover (but not more growth). Interestingly, higher average income and housing values tend to predict less CRS activity. One of the most important factors affecting participation is the aggregate housing value in the community (both initially and in terms of growth), perhaps reflective of a larger property tax base to fund mitigation activities (or to warrant protecting). Environmental factors also play a role, as do the flood-risk-related variables. More flood risk, weighted by where people are located rather than land area, predicts more CRS activity. More flood damage experienced recently predicts more CRS activity, but only in the SMM.

Of most interest here is how the spatial mixed models improve the fit over the OLS approach. In particular, the statistically significant $\lambda$ spatial lag parameter $(z$-stat $=16.7)$ indicates a strong and positive substantive spillover or "contagion" effect. This kind of diffusion is distinct from the idea of spatially correlated unobservables in the model, thus pointing to some substantive spillovers or diffusion effects in spite of the many control variables and in spite of the relative rarity of CRS participation across the full sample. Conditional on all of these demographic, environmental, and flood risk controls, 
Table 1: Variable descriptions.

\begin{tabular}{|c|c|}
\hline Variable name & Description \\
\hline Totalyr & Point total in CRS for community $(0,500+)$ in year $y r$ \\
\hline$\Delta$ Total & Total CRS points in 2013 - Total CRS points in 1998 \\
\hline popdens 98 & Community population per area in 1998 \\
\hline$\%$ white 00 & $\%$ white in 2000 \\
\hline$\%$ adult00 & $\%$ adults (age 18 and older) in 2000 \\
\hline \%kids00 & $\%$ children (under age 5 ) in 2000 \\
\hline$\%$ college 00 & $\%$ with college degree (or more) in 2000 \\
\hline smenty00 & $\%$ living in same county 5 years prior, in 2000 \\
\hline$\%$ poverty 00 & $\%$ under poverty line in 2000 \\
\hline \%unemploy00 & $\%$ unemployed in 2000 \\
\hline income 00 & $\begin{array}{l}\ln \text { (family income) in } 2000 \text {, inflation adjusted to } 2010 \text { (Population- } \\
\text { weighted average of tracts' median family incomes) }\end{array}$ \\
\hline houseval00 & $\begin{array}{l}\text { In(median housing value) in 2000, inflation adjusted to } 2010 \\
\text { (Population-weighted average of tracts' median housing value) }\end{array}$ \\
\hline aggval00 & ln(aggregate housing value) in 2000, inflation adjusted to 2010 \\
\hline$\%$ renter00 & $\%$ of housing units that are renter-occupied in 2000 \\
\hline popgro0090 & Population growth rate from 1990 to 2000 \\
\hline$\%$ college 1000 & $\%$ college $10 / \%$ college 00 \\
\hline income 1000 & income $10 /$ income 00 \\
\hline houseval1000 & houseval10/houseval00 \\
\hline aggval1000 & aggval10/aggval00 \\
\hline rural & $\begin{array}{l}\text { Rural-urban influence code ( } 0-9 \text {, with } 9 \text { being more rural), county- } \\
\text { level }\end{array}$ \\
\hline JulHumid & July humidity, county-level \\
\hline watershare & $\%(0-100)$ of county covered in water, county-level \\
\hline flat & Dummy indicating flat topography, county-level \\
\hline FloodDam598 & $\begin{array}{l}\text { Total property damage per capita from major flood events in county } \\
\text { 1994-1998 }\end{array}$ \\
\hline FloodDam98 & $\begin{array}{l}\text { Total property damage per capita from major flood events in county } \\
\text { in } 1998\end{array}$ \\
\hline noFIRM & $\begin{array}{l}\text { Dummy indicating community does not have a flood plain map } \\
\text { variable defined }\end{array}$ \\
\hline RiskshareA & $\begin{array}{l}\text { Flood risk (0-99) as an area-weighted average of (average) tract } \\
\text { flood risk in community }\end{array}$ \\
\hline RiskshareP & $\begin{array}{l}\text { Flood risk (0-99) as population-weighted average of (average) tract } \\
\text { flood risk in community in } 1998\end{array}$ \\
\hline FloodDam59890 & FloodDam598/FloodDam590 \\
\hline RiskshareP9890 & RiskshareP98/RiskshareP90 \\
\hline
\end{tabular}


Table 2: Summary statistics $(\mathrm{N}=18,165)$.

\begin{tabular}{|c|c|c|c|c|}
\hline Variables & Mean & Std. Dev. & Min. & Max. \\
\hline Total13 & 77.24 & 368.08 & 0 & 5,315 \\
\hline$\Delta$ Total & 46.18 & 257.55 & $-2,066$ & 3,883 \\
\hline popdens98 & $3.1 \mathrm{E}-04$ & 7.2E-04 & $8.16 \mathrm{E}-08$ & 0.03 \\
\hline$\%$ white 00 & 0.87 & 0.17 & 0.002 & 1 \\
\hline$\%$ adult00 & 0.74 & 0.04 & 0.44 & 1 \\
\hline \%kids00 & 0.06 & 0.01 & 0 & 0.20 \\
\hline$\%$ college 00 & 0.13 & 0.09 & 0.003 & 0.64 \\
\hline smenty00 & 0.80 & 0.09 & 0.02 & 0.99 \\
\hline$\%$ poverty 00 & 0.05 & 0.03 & 0 & 0.46 \\
\hline \%unemploy00 & 0.12 & 0.07 & 0 & 0.68 \\
\hline income 00 & 10.98 & 0.32 & 9.63 & 12.44 \\
\hline houseval00 & 11.69 & 0.56 & 2.94 & 14.05 \\
\hline aggval00 & 19.21 & 1.48 & 9.63 & 26.87 \\
\hline$\%$ renter00 & 0.28 & 0.11 & 0.01 & 0.99 \\
\hline popgro0090 & 1.15 & 0.42 & 0.24 & 32.86 \\
\hline \%college1000 & 1.22 & 0.32 & 0 & 9.92 \\
\hline income 1000 & 1.01 & 0.13 & 0 & 3.15 \\
\hline houseval1000 & 1.28 & 2.83 & 0 & 337.79 \\
\hline aggval1000 & 2.22 & 2.80 & 0 & 185.42 \\
\hline rural & 3.73 & 2.91 & 0 & 9 \\
\hline JulHumid & 57.57 & 13.22 & 14 & 80 \\
\hline watershare & 7.02 & 14.03 & 0 & 75 \\
\hline flat & 0.51 & 0.50 & 0 & 1 \\
\hline FloodDam598 & 129.09 & $1,458.15$ & 0 & $64,975.34$ \\
\hline FloodDam98 & 26.47 & 292.17 & 0 & $10,193.89$ \\
\hline noFIRM & 0.16 & 0.36 & 0 & 1 \\
\hline RiskshareA & 53.63 & 21.48 & 3.38 & 99 \\
\hline RiskshareP & 36.03 & 26.78 & 0.004 & 99 \\
\hline FloodDam59890 & $5,185.57$ & $98,124.41$ & 0 & $2,298,142$ \\
\hline RiskshareP9890 & 1.01 & 0.08 & 0.42 & 7.28 \\
\hline
\end{tabular}


Table 3: OLS and SMM regression results.

\begin{tabular}{|c|c|c|c|}
\hline Variable & $\begin{array}{l}\text { OLS (Total13) } \\
\text { Coef. }\end{array}$ & $\begin{array}{l}\text { SMM (Total13) } \\
\text { Coef. }\end{array}$ & $\begin{array}{l}\text { SMM ( }(\Delta \text { Total }) \\
\text { Coef. }\end{array}$ \\
\hline popdens98 & $-3.50 \mathrm{E}+04 * * *$ & $-3.20 \mathrm{E}+04 * * *$ & $-20840.1 * * *$ \\
\hline$\%$ white 00 & $-60.410 * * *$ & 13.988 & 9.261 \\
\hline$\%$ adult00 & 107.183 & $249.845^{* *}$ & 33.405 \\
\hline \%kids00 & $-506.765^{*}$ & -16.312 & -218.114 \\
\hline$\%$ college 00 & $381.333 * * *$ & $363.883 * * *$ & $182.306^{* * *}$ \\
\hline smenty00 & $-318.110^{* * *}$ & $-186.274 * * *$ & $-105.222 * * *$ \\
\hline$\%$ poverty 00 & -58.472 & -0.611 & -21.213 \\
\hline \%unemploy00 & $-226.833^{* * *}$ & -146.538 & -54.932 \\
\hline income 00 & $-200.034 * * *$ & $-142.544 * * *$ & $-78.694 * * *$ \\
\hline houseval00 & $-44.904 * * *$ & $-40.905 * * *$ & $-17.773 * * *$ \\
\hline aggval00 & $103.131^{* * *}$ & $68.597 * * *$ & $33.704 * * *$ \\
\hline$\%$ renter00 & $156.890 * * *$ & $152.238^{* * *}$ & $102.015^{* * *}$ \\
\hline popgro0090 & $-10.947^{* *}$ & $-17.138^{*}$ & -1.914 \\
\hline$\%$ college 1000 & 19.855 & $18.592 * *$ & $10.052 *$ \\
\hline income 1000 & -4.764 & -11.506 & -10.825 \\
\hline houseval1000 & 0.570 & 0.242 & 0.131 \\
\hline aggval1000 & $8.005^{* * *}$ & $5.575 * * *$ & $2.556 * * *$ \\
\hline Rural & $-6.630 * * *$ & -1.417 & -0.847 \\
\hline JulHumid & $-0.488^{*}$ & -0.184 & 0.071 \\
\hline Watershare & $1.342 * * *$ & $1.027 * * *$ & $0.303 * *$ \\
\hline Flat & $29.203^{* * *}$ & $27.067 * * *$ & $16.373^{* * *}$ \\
\hline FloodDam598 & 0.008 & $0.008 * * *$ & $0.005 * * *$ \\
\hline FloodDam98 & -0.013 & -0.011 & -0.006 \\
\hline noFIRM & 7.458 & 4.391 & 5.045 \\
\hline RiskshareA & $-1.254 * * *$ & $-0.621 * * *$ & -0.171 \\
\hline RiskshareP & $1.763 * * *$ & $1.124 * * *$ & $0.409 * * *$ \\
\hline FloodDam59890 & $5.00 \mathrm{E}-05^{*}$ & $3.09 \mathrm{E}-05$ & $9.40 \mathrm{E}-06$ \\
\hline RiskshareP9890 & $212.122 * * *$ & $207.990 * * *$ & $147.18^{* * *}$ \\
\hline Constant & $816.458 * * *$ & 424.760 & 300.879 \\
\hline Spatial lag: $\lambda$ & & $0.058 * * *$ & $0.065 * * *$ \\
\hline Spatial error: $\rho$ & & $-0.025^{* * *}$ & $-0.046 * * *$ \\
\hline $\mathrm{N}$ & 18,165 & 18,165 & 18,095 \\
\hline $\mathrm{F}$ & $25.73^{* * *}$ & 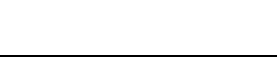 & \\
\hline
\end{tabular}


communities with neighbors that undertake more CRS activity tend to undertake more flood management themselves. Further, the statistically significant spatial error parameter $(\rho)$ indicates that there is some spatial autocorrelation in the error term, albeit it is small and (surprisingly) negative. Thus, the results point to some substantial spatial dependence in the data that a basic OLS approach would overlook.

One key variable of particular note is RiskshareP9890. This variable captures the extent to which a community had its population-weighted flood risk change from 1990-1998 in the lead-up to the first year in our CRS data. Because our flood risk measure itself is time invariant, this change owes entirely to changing population. Thus, communities that are experiencing faster population growth in the riskier parts of the community, according to these results, tend to have earned more CRS points. This is true for both the cross-section of points in 2013 as well as the change in points from 1998-2013. The results here suggest that communities with more flood risk tend to participate more in the CRS, and this effect is even stronger when their populations are growing faster in riskier areas. That these effects survive the spatial controls in the SMM suggest a very robust result.

The results in the second and third columns in Table 3 exhibit considerable parallels, indicating the patterns evident overall participation in the CRS are similar to those in the past 15 years of CRS dynamics. Despite the substantially different dependent variable between models, 24 of 25 parameters estimated (and all of the statistically significant parameters) share the same sign. Sixteen parameters share sign and significance, and only two parameters that are significant in column 2 (Total13) are insignificant in column 3 ( $\Delta$ Total) at the 5\% level. Thus, even though the coefficients' magnitudes differ as expected because the dependent variables differ, Table 3 suggests that the drivers of the initial and eventual extents of local flood management do not differ much. Both models show strong positive roles for aggregate housing values (and negative roles for average house prices) and rentership rates, recent flood events and populations in flood-prone areas, low density, and education levels.

This similarity extends to the spatial diffusion parameters in the SMM. Neighbors' participation in the CRS positively affects a community's level of participation, whether it is measured in levels of participation in 2013 or as changes in participation from 1998-2013. Both sets of results indicate a strong policy diffusion process whereby a communities' CRS flood management activity is positively affected by the activity of its neighboring communities. The positive spatial lag suggests that a community's flood management activity (measured as levels of 2013 activity or as new activity since 1998) directly influences its neighbors' adoption of CRS flood management activities, even after controlling for a host of flood risk, environmental, and other community characteristics. In addition, the similar, negative autocorrelation parameter $\rho$ in both models points to an unexpected pattern of negatively spatially correlated unobservables. Although we typically expect the unobserved factors in adoption decisions to positive spatially correlate or cluster, here both models show the reverse. After controlling for many observables and the direct spillover of flood management policies among neighbors, both models show negatively correlated errors. For communities adopting more CRS activities than the model predicts, they tend to have neighbors that adopt fewer CRS activities. Such a result resembles a patter than we might expect if communities are free-riding on their neighbors' costly management efforts. These models have also been estimated as linear probability models (where the dependent variable is a binary variable for whether a community has joined), and the results are very similar in sign and significance for most parameters. 


\section{CONCLUSION}

Establishing the strong and robust roles of certain community, environmental, and risk factors in explaining cities' and counties' decisions to participate in the CRS program offers important indicators of the forces that systematically drive adoption of community risk management programs. Even after controlling for spatial dependence in the data, key demographic and environmental factors retain their strong influence. Aggregate housing value and population exposed to high flood risk are consistently important predictors. The role of renter-occupancy rates and housing stock variables may suggest more local mobilization and advocacy efforts that are pushing politicians to participate in CRS. The evidence is consistent with politicians and public managers being pressured by more property owners to intensify their CRS participation (as this would result in greater discounts on insurance premiums).

This study also finds that environmental factors and flood-risk-related variables play a role in communities' participation in CRS. This gives credence to previous studies that report evidence of flood risk being an important predictor of community participation in the CRS [7], [11], [12], [15]. Early indications suggest that CRS activities with great physical spillovers and easy-to-diffuse components (e.g. public outreach, flood hazard maps, hazard disclosure, map information services, flood data maintenance) that concurrently improve awareness and knowledge of environmental and flood-risk-related factors are important to CRS diffusion to neighboring communities.

The results here offer some of the first evidence of spatial interdependence in local flood management activity, even after controlling for a rich set of community characteristics and environmental factors. That the spatial lag parameter exhibits a positive contagion - whereby more activity by neighbors predicts more activity by a community - dominates these spatial models and shows a direct and strong, if unsurprising, role for policy diffusion. These results also point to a more surprising finding: negative spatial autocorrelation. Though tricky to interpret in an SMM, we find that a community with neighbors who have unexpectedly high CRS scores (in terms of regression residuals) significantly predicts unexpectedly low CRS scores in that community. In other words, when neighbors do "extra" CRS management activity, conditional on many controls, a community is prone to doing "less". These results may point to some initial evidence of free-riding among communities.

Concerns about the diffusive capacity of the CRS and its individual components can be addressed by looking to lessons from the policy diffusion literature. For instance, in examining why certain policy intervention diffuse easier than others, [26] and [27] highlight the policy's complexity, relative advantage, compatibility, observability, and "trialability." Therefore, how can the CRS and its individual components be improved in terms of suitability to local contexts, ease of comprehension and application, as well as the ability to demonstrate visible benefits in an environment supportive of voluntary trials? Additionally, consultative homegrown approaches are often encouraged to promote the various components of the CRS. Though this can positively enhance the sustainability of actions and activities, it typifies an "Achilles heel" of programs like this in terms of diffusion: encouraging communities to look inwards may inhibit policy diffusion mechanisms.

Passive approaches of just relying on contagion, on initial adopters to diffuse more widely, may fall short of more aggressive policy aims. Passive approaches can be complemented with active efforts at linking communities. Notably, the CRS scheme makes no allowance for watershed-related interdependencies, any regional approaches, or even explicitly leveraging overlapping jurisdictions. Even a mentoring program could allow participants to earn points by sharing expertise and providing support to neighboring communities. Given the implicit 
costs (e.g., additional insurance premium discounts in the NFIP), such approaches might do well to target particularly costly regions.

On a general scale, flood risks, community characteristics, and environmental factors play key roles in influencing CRS participation. This study extends the literature by pointing to a strong and robust role of policy diffusion, specifically an interdependence among neighboring communities, in local flood management decisions. While past work has overlooked this aspect in assuming that adoption decisions are independent, recognizing and leveraging these interdependencies is an important area for future research.

\section{ACKNOWLEDGEMENT}

This material is based upon work supported by the National Science Foundation under Grant No. 1635381.

\section{REFERENCES}

[1] Arimura, T.H., Hibiki, A. \& Katayama, H., Is a voluntary approach an effective environmental policy instrument? A case for environmental management systems. Journal of Environmental Economics and Management, 55(3), pp. 281-295, 2008.

[2] Lyon, T.P. \& Maxwell, J.W., "Voluntary" approaches to environmental regulation. Economic Institutions and Environmental Policy, eds M. Franzini \& A. Nicita, Ashgate Publishing: Aldershot, UK, pp. 75-120, 2002.

[3] Potoski, M. \& Prakash, A., Green clubs and voluntary governance: ISO 14001 and firms' regulatory compliance. American Journal of Political Science, 49(2), pp. 235248, 2005.

[4] Haufler, V., A Public Role for the Private Sector: Industry Self-Regulation in a Global Economy, Carnegie Endowment for International Peace: Washington, DC, 2013.

[5] Jonkman, S.N., Global perspectives on loss of human life caused by floods. Natural Hazards, 34(2), pp. 151-175, 2005.

[6] Kreibich, H., Müller, M., Thieken, A.H. \& Merz, B., Flood precaution of companies and their ability to cope with the flood in August 2002 in Saxony, Germany. Water Resources Research, 43(3), 2007.

[7] Sadiq, A.A. \& Noonan, D.S., Flood disaster management policy: An analysis of the United States Community Ratings System. Journal of Natural Resources Policy Research, 7(1), pp. 5-22, 2015.

[8] Gopalakrishnan, C., Water and disasters: A review and analysis of policy aspects. International Journal of Water Resources Development, 29(2), pp. 250-271, 2013.

[9] Sadiq, A.A. \& Noonan, D.S., Local capacity and resilience to flooding: Community responsiveness to the Community Ratings System Program incentives. Natural Hazards, 78(2), pp. 1-16, 2015.

[10] National Weather Service, United States Flood Loss Report - Water Year 2012, Online. www.nws.noaa.gov/hic/summaries/WY2012.pdf. Accessed on: 15 Apr. 2014.

[11] Landry, C.E. \& Li, J., Participation in the community rating system of NFIP: Empirical analysis of North Carolina counties. Natural Hazards Review, 13, pp. 205-220, 2012.

[12] Posey, J., The determinants of vulnerability and adaptive capacity at the municipal level: Evidence from floodplain management programs in the United States. Global Environmental Change, 19(4), pp. 482-493, 2009.

[13] Brody, S.D., Zahran, S., Highfield, W.E., Bernhardt, S.P. \& Vedlitz, A., Policy learning for flood mitigation: A longitudinal assessment of the Community Rating System in Florida. Risk Analysis, 29(6), pp. 912-929, 2009. 
[14] Zahran, S., Weiler, S., Brody, S.D., Lindell, M.K. \& Highfield, W.E., Modeling national flood insurance policy holding at the county scale in Florida, 1999-2005. Ecological Economics, 68(10), pp. 2627-2636, 2009.

[15] Zahran, S., Brody, S.D., Highfield, W.E. \& Vedlitz, A., Non-linear incentives, plan design, and flood mitigation: The case of the federal emergency management agency's community rating system. Journal of Environmental Planning and Management, 53(2), pp. 219-239, 2010.

[16] Alberini, A. \& Segerson, K., Assessing voluntary programs to improve environmental quality. Environmental \& Resource Economics, 22(1), pp. 157-184, 2002.

[17] Arora, S. \& Cason, T.N., An experiment in voluntary environmental regulation: Participation in EPA's 33/50 program. Journal of Environmental Economics and Management, 28(3), pp. 271-286, 1995.

[18] Darnall, N., Motivations for participating in a voluntary environmental initiative: the multi-state working group and EPA's EMS pilot program. Research in Corporate Sustainability, eds S. Sharma \& M. Starik, Edward Edgar Publishing: London, pp. 123-154, 2003.

[19] Darnall, N. \& Sides, S., Assessing the performance of voluntary environmental programs: Does certification matter? Policy Studies Journal, 36(1), pp. 95-117, 2008.

[20] Delmas, M. \& Keller, A., Free riding in voluntary environmental programs: The case of the U.S. EPA WasteWise program. Policy Sciences, 38(2-3), pp. 91-106, 2005.

[21] Khanna, M., Non-mandatory approaches to environmental protection. Journal of Economic Surveys, 15(3), pp. 291-324, 2002.

[22] Videras, J. \& Alberini, A., The appeal of voluntary environmental programs: Which firms participate and why? Contemporary Economic Policy, 18(4), pp. 449-460, 2000.

[23] Burby, R.J., Flood insurance and floodplain management: The US experience. Global Environmental Change Part B: Environmental Hazards, 3(3), pp. 111-122, 2001.

[24] Federal Emergency Management Agency, National Flood Insurance Community Rating Systems Coordinator's Manual, FIA-15/2017, OMB No. 1660-0022, Online. www.fema.gov/media-library/assets/documents/8768. Accessed on: 3 Apr. 2018.

[25] United States Department of Transportation, Natural Disaster Study: National Pipeline Risk Index Technical Report (Task 2), Online. www.npms.phmsa.dot.gov/data/data_natdis.htm. Accessed on: 1 Apr. 2014.

[26] Makse, T. \& Volden, C., The role of policy attributes in the diffusion of innovations. The Journal of Politics, 73(1), pp. 108-124, 2011.

[27] Shipan, C.R. \& Volden, C., Policy diffusion: Seven lessons for scholars and practitioners. Public Administration Review, 72(6), pp. 788-796, 2012. 